\title{
A Rare Cause of Acute Back Pain in a Young Adult: Case Report and Discussion of Calcific Discitis
}

\author{
Paul Schulze ${ }^{1 *}$, Colin O'Connor ${ }^{2}$, Neil Anand ${ }^{1}$, Peter Wynne $^{1}$ \\ 1. Department of Radiology, Morristown Medical Center, Morristown, NJ \\ 2. St. George's University, Grenada, West Indies \\ * Correspondence: Paul Schulze, Morristown Medical Center, 100 Madison Ave, Morristown, NJ 07960, USA

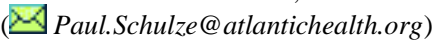 \\ Radiology Case. 2020 Oct; 14(10):1-9 :: $\quad$ DOI: $10.3941 /$ jrcr.v14i10.3728
}

\begin{abstract}
Calcific discitis in the adult population is very rare, with fewer than 40 cases reported in the literature. Most cases thus far have involved patients presenting with mid to upper back pain of acute to subacute onset. As it is a condition that is self-resolving with rare exception, the true incidence is likely underestimated. Another factor contributing to the underestimation of individuals with back pain in general is that many patients will treat themselves before presenting for care. Back pain is one of the most common presenting symptoms to primary care physician offices and represents an economic burden of billions of dollars annually. The utilization of MRI imaging and other diagnostic work-up amount to an important component of this cost and one that could possibly be reduced with early radiological identification of this condition. We present a case in which an adult patient presented with subacute lumbar back pain, eventually diagnosed as calcific discitis.
\end{abstract}

\section{CASE REPORT}

\section{CASE REPORT}

A 24-year-old female with a past medical history of mononucleosis and atrial septal defect presented with an approximately one-month history of progressive back pain. She developed lower back pain after carrying heavy bags and weeding at work as a stable hand. She was evaluated in the emergency department and lumbar spine radiographs were obtained. Radiographs revealed a nonspecific area of calcification in the region of the L1-L2 intervertebral disc space with no evidence of acute fracture, subluxation, or malalignment (Figure 1).

For further characterization a CT of the lumbar spine was performed (Figures 2 and 3). CT demonstrated hyperdense material within the L1-L2 intervertebral disc space with extension superiorly through the inferior endplate of L1. Increased density was noted along the inferior aspect of L1 consistent with sclerosis. There was question of an acute to subacute fracture through the inferior endplate of L1 or a Schmorl's node. An MRI of the spine was then performed, showing calcification involving the intervertebral disc space at L1-L2 extending superiorly through the inferior endplate of L1 (Figures 5 and 6). There was associated extensive edema involving the L1 vertebral body with enhancement.

Given the CT and MRI findings, the concern for osteomyelitis was raised as well as the possibility of calcific discitis. The patient was admitted for a course of IV antibiotics as well as an IR guided biopsy of the region of interest. The biopsy culture was subsequently negative. Her 
pain improved during the hospital course and was discharged after a week to follow up with her orthopedist.

Her functional status has improved since onset of symptoms, however some soreness and difficulty ambulating persisted. She noted pain improved with rest and was exacerbated by activity. She had a follow up MRI performed approximately 4 months after onset of symptoms (Figure 8). The MRI showed persistent edema along the L1-L2 endplates which was slightly improved in relation to the comparison exams. The patient is currently undergoing conservative treatment and is followed by her orthopedist.

\section{DISCUSSION}

\section{Etiology \& Demographics:}

Calcific discitis is a rare condition in the adult population with less than 40 cases cases found through Pubmed $[1,2,3,5,7]$. The etiology and pathophysiology of the disease is poorly understood and any proposed theories are based on studies in the pediatric population where CD is much more common. [3] The process of disc calcification is presumed to be centered around the vascular supply of the cartilaginous end-plate and of the disc itself. These vascular changes can be a result of microtrauma, infection, or inflammation. This can be due to either the abrupt loss of blood supply prior to obliteration of the small vessels supplying the end-plate leading to necrosis and eventual calcification. Interestingly, the abnormal presence of a blood supply to the normally avascular nucleus pulposus, either from trauma or an inflammatory response post viral infection can lead to calcification. Again, these mechanisms have been studied in the pediatric population as adult $\mathrm{CD}$ is largely idiopathic. There is a predilection of adult calcific discitis in female patients, with females making up approximately two-thirds of cases [1]. Conversely, males are more likely to be affected in the pediatric age group.

\section{Clinical \& Imaging Findings}

Though much of the literature deals with discitis in the pediatric population, some unique characteristics are found in adults. Calcific discitis in the pediatric population involves the nucleus pulposus of cervical discs and is typically temporary with resolution of calcification on serial radiographs, while discitis in adults is often limited to the annulus fibrosus of thoracic vertebrae and may persist for months or years. In fact, all but two reported cases of CD involved strictly the thoracic vertebra; a female patient whose calcification was found within the C2-C3 vertebrae and a male patient who had multiple levels of calcification, most inferiorly at the T12/L1 disc space and another patient discussed below. Presentation often involves the abrupt onset of severe back or neck pain, though more severe presentations have been documented $[3,4,8,9]$. For example, one patient presented with back pain and sciatica that was initially managed with analgesia [6]. She returned 24 months later with right leg weakness and fecal incontinence in addition to worsening sciatica. Another patient's 4-day history of upper lumbar pain and bilateral sciatica rapidly escalated to burning and numbness and eventually bilateral lower limb paralysis and bladder incontinence in a matter of hours after herniation of the involved disc [7]. X-ray and CT will demonstrate calcification of the disc, typically confined within the nucleus pulposus or extending into the annulus fibrosus. There may or may not be intravertebral herniation of the disc into the adjacent vertebral body. Erosion of the endplate is not usually present though sclerosis may be visualized. MRI will show a hypointense signal on $\mathrm{T} 1$ and $\mathrm{T} 2$ within the intervertebral disc with marrow edema of the vertebral body, again likely without endplate destruction [5]. Though osseous edema may be the first imaging finding, bone tumors such as osteoid osteomas or osteosarcomas will also demonstrate marrow edema [10]. CT is thus necessary to demonstrate calcification of the disc which is not found in tumors or inflammatory processes of the bone. Bone marrow edema within the vertebral bodies and intervertebral disc space on MRI, coupled with calcification of the intervertebral disc space on $\mathrm{CT}$ should alert the radiologist to a possible diagnosis of calcific discitis.

\section{Treatment \& Prognosis}

Because initial imaging findings of calcific discitis may not be apparent on x-ray and only visualized with MRI, this entity requires a high degree of clinical suspicion to order the appropriate imaging without delay. This would help avoid costly imaging such as a bone scan when osteomas, osteoblastomas or metastasis to the spine are suspected. With so few adult cases reported, it is not surprising that there exists no management guidelines for calcific discitis. Though treatment is typically conservative, with activity restriction and NSAIDs, surgical intervention has been necessary in select cases $[1,4,5,9]$. The severity of impairment on initial presentation does not seem to be prognostic. One patient who quickly developed fecal incontinence was managed medically and her condition resolved. The patient with paralysis mentioned above required laminectomy involving several vertebrae, pedicle fixation, and intertransverse fusion. The patient regained near complete function and sensation of affected areas. The majority of adult calcific discitis patients show improvement with only conservative treatment and thus the prognosis is quite good [1].

\section{Differential Diagnosis}

\section{Infective spondylodiscitis}

Similar to calcific discitis in that the entities that affect adults and children are unique in many respects, infective spondylodiscitis, or simply diskitis-osteomyelitis is an infection of the intervertebral disk and/or vertebrae. As it is an infection, risk factors include many disease states involving immunosuppression or conditions predisposing to infection such as diabetes mellitus, chronic systemic steroid use, intravenous drug use, advanced age, or cancer. Though typically involving the lumbar spine, back pain, like in $\mathrm{CD}$, is the most common presenting symptom. X-ray will reveal nonspecific findings early in the disease until several weeks later when intervertebral disk space narrowing, end-plate involvement, and possibly sclerosis of the bone will be evident. Thickening of the paravertebral tissues may be visualized. CT, allowing greater resolution, especially early in the disease course, will confirm any plain film findings such as narrowing of intervertebral disc space, end plate involvement, and erosive changes. T1-weighted MRI will show hypointensity or isointensity while T2-weighted MRI 
will show hyperintensity of the endplates and within the intervertebral disc. There will be loss of endplate definition and diminished height of intervertebral disc. Gadolinium contrast MRI will show enhancement of the subchondral bone or vertebral body. PET scan, with 18F-FDG yields increased uptake in spinal infection versus normal bone marrow in degenerative processes and has high sensitivity and negative predictive value making it the radionuclide test of choice.

\section{Osteoid osteoma}

Osteoid osteomas are found primarily in children and have a male predilection. Presentation involves nighttime pain, and though not limited to the spine, can lead to a painful scoliosis. X-ray can show periosteal reaction with cortical thickening. Occasional the center can be visualized as a circumscribed lucent region. CT, the modality of choice, enhances the characteristics found on x-ray, with a lucent center and surrounding sclerosis. MRI is nonspecific and will show hyperemia and surrounding bone marrow edema falsely suggesting an aggressive pathology. US may show hypoechogenic center with surrounding posterior acoustic enhancement. The hallmark feature of a PET scan is a "double-density" sign consisting of two concentric rings of intense uptake with the center ring having increased intensity.

\section{Osteoblastoma}

Though more often presenting in young adults compared to children, this entity, like osteoid osteoma, can present with a painful scoliosis when they involve the spine or a gradual dull pain predominating at night. Osteoblastomas can be found in the spine in up to $40 \%$ of patients. Unlike osteoid osteomas, osteoblastomas are not responsive to NSAID's. X-ray may show internal calcifications. Similar to osteoid osteomas, the $\mathrm{x}$-ray findings of a surrounding reactive sclerosis is better visualized on CT. T1-weighted MRI can show hypointense to isointense and T2-weighted MRI typically demonstrates isointense to hypointense lesions. Both T1 and T2 may show decreased intensity in the area of calcification. Due to its highly vascular nature, contrast-enhanced MRI is avid. PET scan shows a non-specific intense uptake.

\section{Intervertebral disc herniation/bulge}

Intervertebral disc herniation and bulge can both result in back pain and neurological symptoms. Back pain is one of the most common patient complaints to primary care physicians and thus both of these entities must be included in the differential of back pain. Any disc material that is greater than $50 \%$ of the circumference of the total disc is considered a disc bulge and anything less is qualified as either a disc protrusion or disc extrusion. Extrusion refers to when the nucleus pulposus is outside the normal margins of the disc and there is no overlying intact annular fibers. This distinction cannot be made on MRI and thus the two herniation varieties are determined based on the relative extension of disc material in the axial plane. Axial and sagittal T2-weighted MRI images are often used to visualize herniations and bulges and MRI remains the gold standard for evaluating the relationship between the disc and the neural structures and soft tissues.

\section{Lumbar spondylosis}

Lumbar spondylosis is due to osteophyte formation at points where annular ligaments are stressed. It is typically asymptomatic and an incidental finding likely secondary to an aging process. Back pain is an unrelated finding and thus $\mathrm{x}$ ray, $\mathrm{CT}$ and $\mathrm{MRI}$ are only indicated when complications exist. Xray and CT will demonstrate horizontal projections from vertebral body margins, most commonly anterior and lateral projections.

\section{TEACHING POINT}

Calcific discitis is a rare cause of acute back pain in adults, more commonly seen in the pediatric population. It is important for the radiologist to be aware of adult calcific discitis in differential considerations as it may present similar to discitis/osteomyelitis or neoplastic disease. Adult calcific discitis is typically confined to the nucleus pulposus with herniation and calcification. CT demonstrates calcification within the intervertebral disc and MR aids in characterization of bone marrow edema of the vertebral bodies.

\section{REFERENCES}

1. Iampreechakul P, Lertbutsayanukul P, Suanprasert N. Acute calcific discitis or symptomatic calcified schmorl's node of the upper thoracic spine in an adult: A case report and literature review. Asian J Neurosurg 2019;14:1021-9. PMID: 31497157

2. Xu N, Wei F, Liu X, Jiang L, Liu Z. Calcific discitis with giant thoracic disc herniations in adults. European Spine Journal May 2016, Volume 25, Supplement 1, pp 204-208. PMID: 26821144

3. Shah A, Botchu R, Grainger MF, Davies AM, James SL. Acute symptomatic calcific discitis in adults: a case report and review of literature. Skeletal Radiology. December 2015, Volume 44, Issue 12, pp 1819-1824. PMID: 26160461

4. Mittal P, Saggar K, Sandhu P, Gupta K. Acute calcific discitis with intravertebral disc herniation in the dorsolumbar spine. Indian J Radiol Imaging. 2010 Aug; 20(3): 205-207. PMID: 21042446

5. Hu S, Niu LS, Zheng WB, Sun T, Sun MY. Paralysis Resulting from Calcific Discitis with Acute Herniation. Chin Med J (Engl). 2017 Nov 5;130(21):2643-2644. PMID: 29067966

6. Azizaddini S, Saeed A, Redjal, N, Walcott B, Mollahoseini R. Adult acute calcific discitis confined to the nucleus pulposus in the cervical spine. Journal of Neurosurgery: Spine. Volume 19 (2013): Issue 2 (Aug 2013): Pages 141-267. PMID: 23746089

7. Bazzi J, Dimar JR, Glassman SD. Acute calcific discitis in adults. Am J Orthop (Belle Mead NJ). 2002 Mar;31(3):141-5. PMID: 11922457

8. Nogueira-Barbosa MH, da Silva Herrero CF, Pasqualini W, Defino HL. Calcific discitis in an adult patient with intravertebral migration and spontaneous remission. Skeletal Radiol. 2013 Aug;42(8):1161-4. PMID: 23532559 
9. Sadek A, Dare C, McGillion S, Nader-Sepahi A, Skiadas V. Calcific discitis with giant thoracic disc herniations in adults. Br J Neurosurg. 2017 Oct 26:1-5. PMID: 29069932

10. Rodacki MA, Castro CE, Castro DS. Diffuse vertebral body edema due to calcified intraspongious disk herniation. Neuroradiology. 2005 May;47(5):316-21. PMID: 15891876

\section{FIGURES}

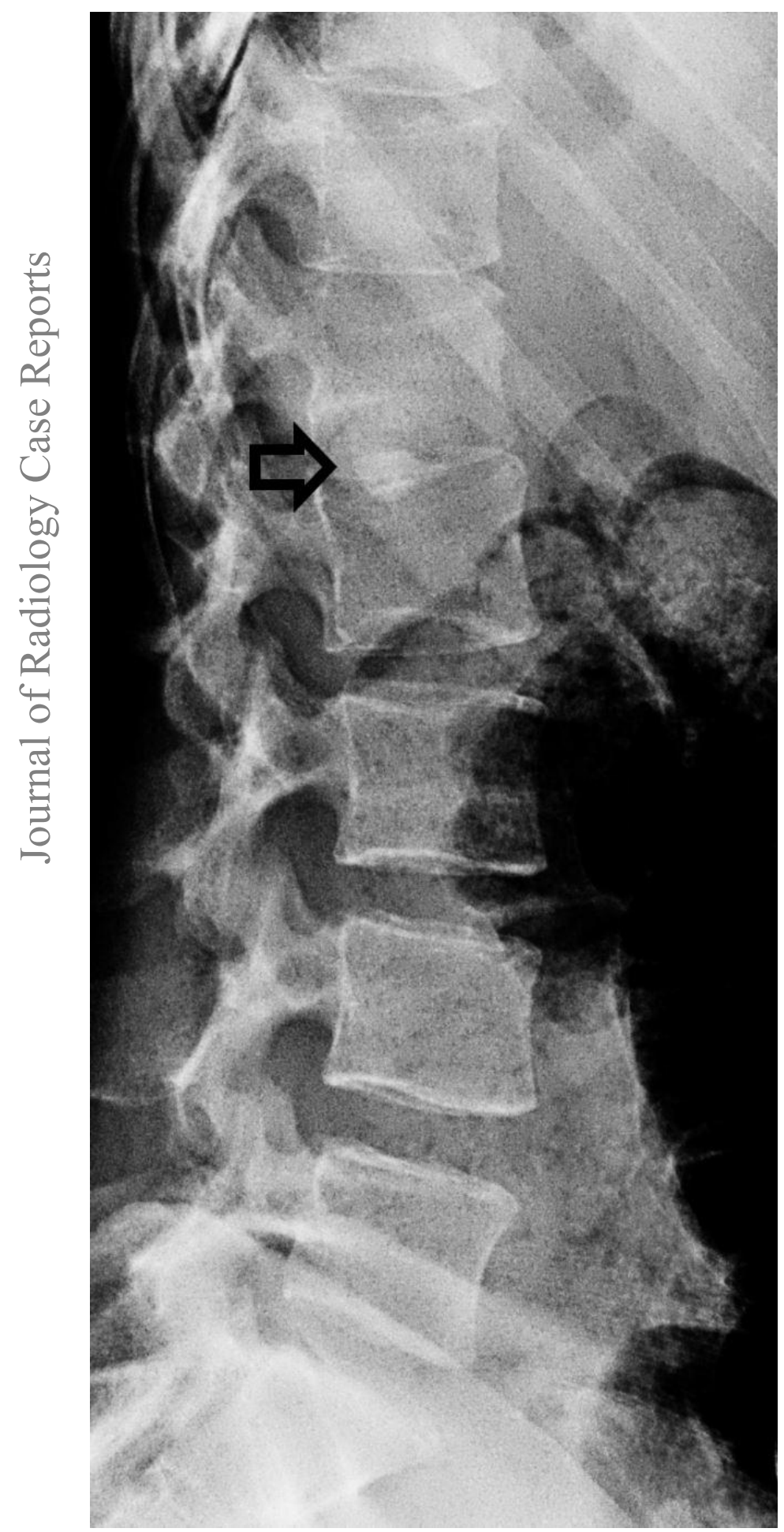

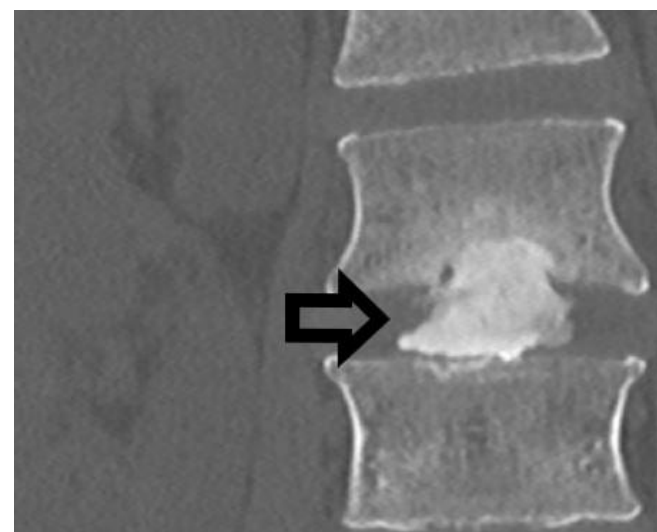
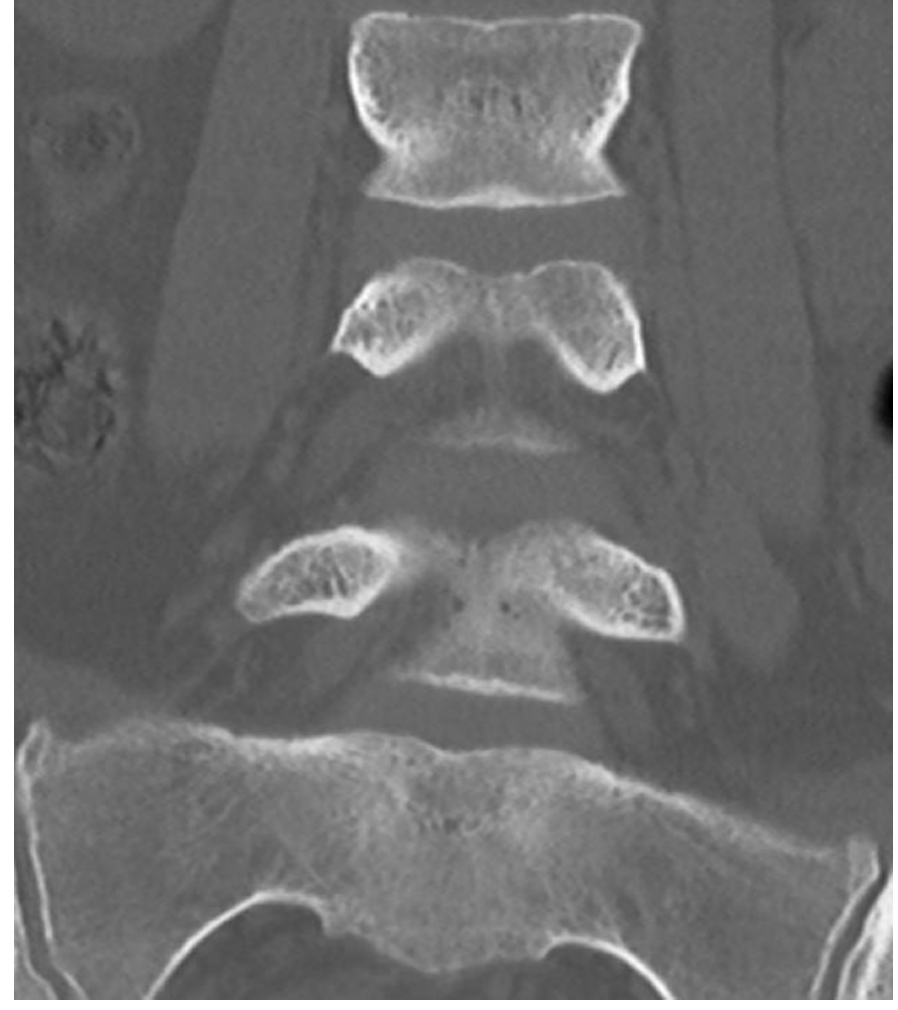

Figure 2 (top): 24-year-old female patient: Diagnosis of Calcific Discitis.

Findings: Coronal CT image of the spine demonstrates hyperdense material within the L1-L2 intervertebral disc space (arrow) with greater extension superiorly through the inferior endplate of L1. There is increased density along the inferior aspect of L1 which is presumed to represent sclerosis.

Technique: $\mathrm{mA}$ 299, kvp 100, $5.0 \mathrm{~mm}$ slice thickness, with 100ml, Omnipaque 350 .

Figure 1 (left): 24-year-old female patient: Diagnosis of Calcific Discitis.

Findings: Lateral radiograph of the lumbar spine demonstrates a focus of calcification at the L1-L2 intervertebral disc space (arrow).

Technique: mA 518, kvp 80. 


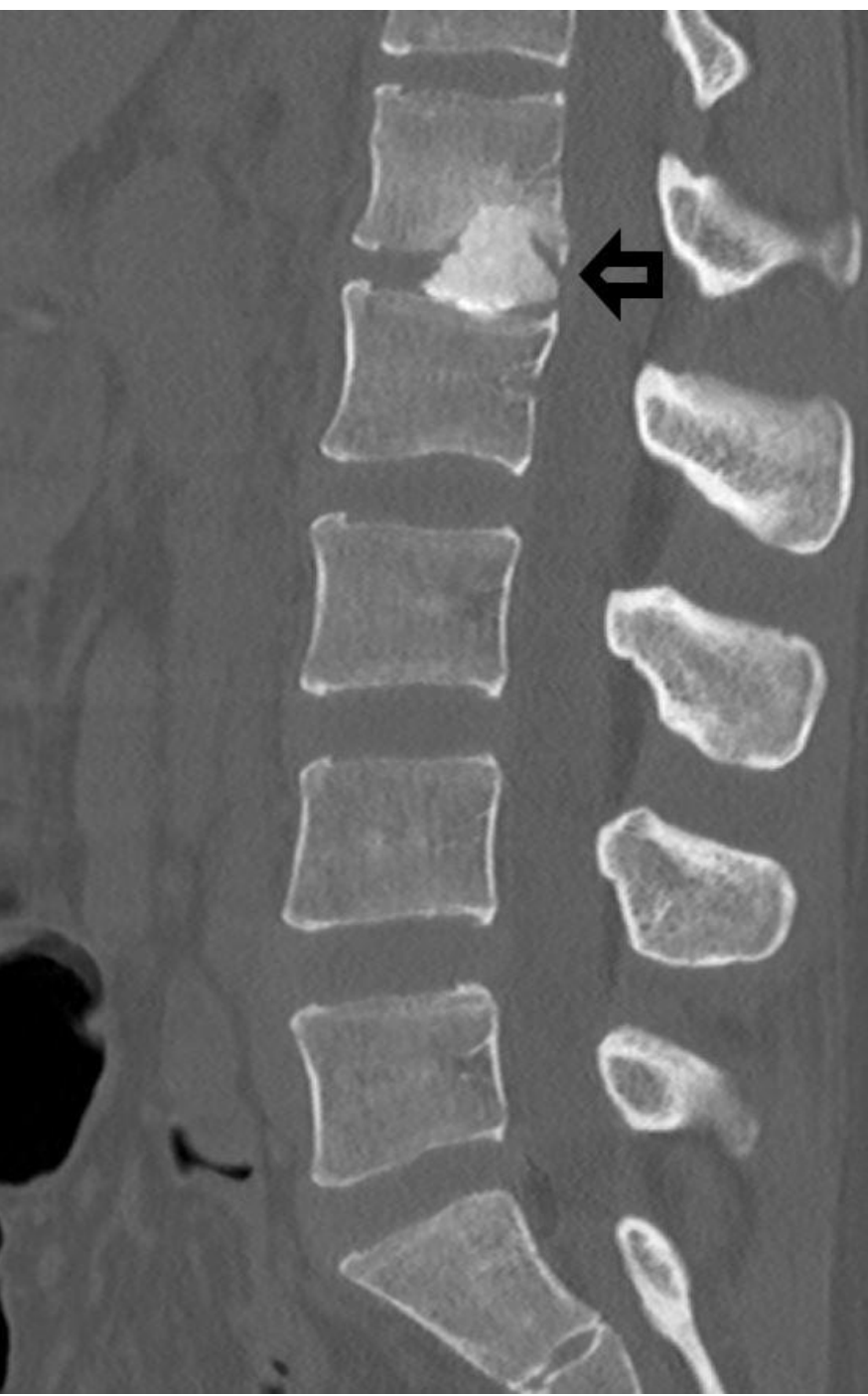

Figure 3: 24-year-old female patient: Diagnosis of Calcific Discitis.

Findings: Sagittal CT image of the spine demonstrates hyperdense material within the L1-L2 intervertebral disc space (arrow) with greater extension superiorly through the inferior endplate of L1. There is increased density along the inferior aspect of $\mathrm{L} 1$ which is presumed to represent sclerosis.

Technique: mA 299, kvp 100, $5.0 \mathrm{~mm}$ slice thickness, with $100 \mathrm{ml}$, Omnipaque 350

Figure 5 (right): 24-year-old female patient: Diagnosis of Calcific Discitis.

Findings: Sagittal T2 image of the spine demonstrates a T2hypointense lesion within the intervertebral disc space at L1L2 (arrow) with marrow edema throughout the L1 vertebral body (arrowhead). There is mild associated spinal canal stenosis.

Technique: Model: Siemens Somatom; TE: 98.12; TR: 3790.

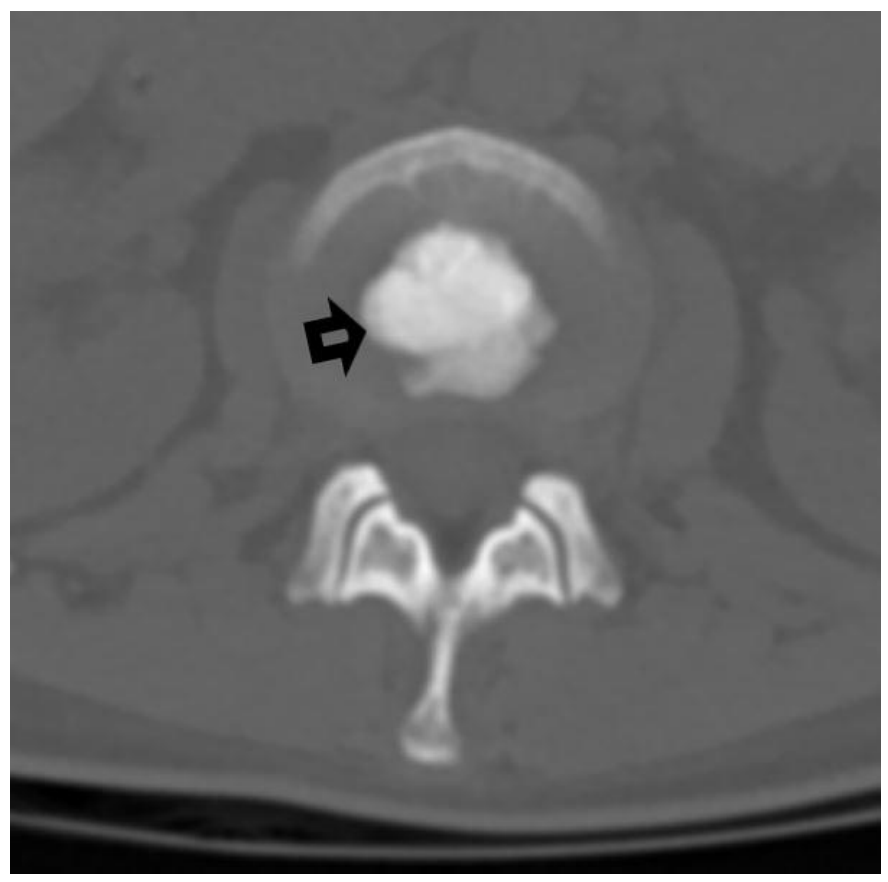

Figure 4: 24-year-old female patient: Diagnosis of Calcific Discitis.

Findings: Axial CT image of the spine demonstrates hyperdense material within the L1-L2 intervertebral disc space (arrow).

Technique: mA 299, kvp 100, $5.0 \mathrm{~mm}$ slice thickness, with 100ml, Omnipaque 350.

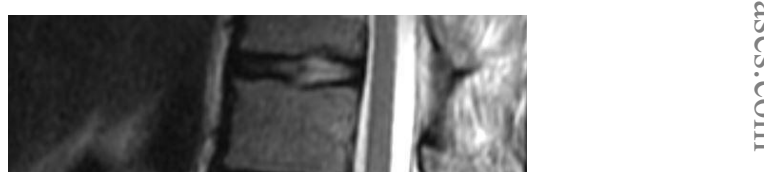




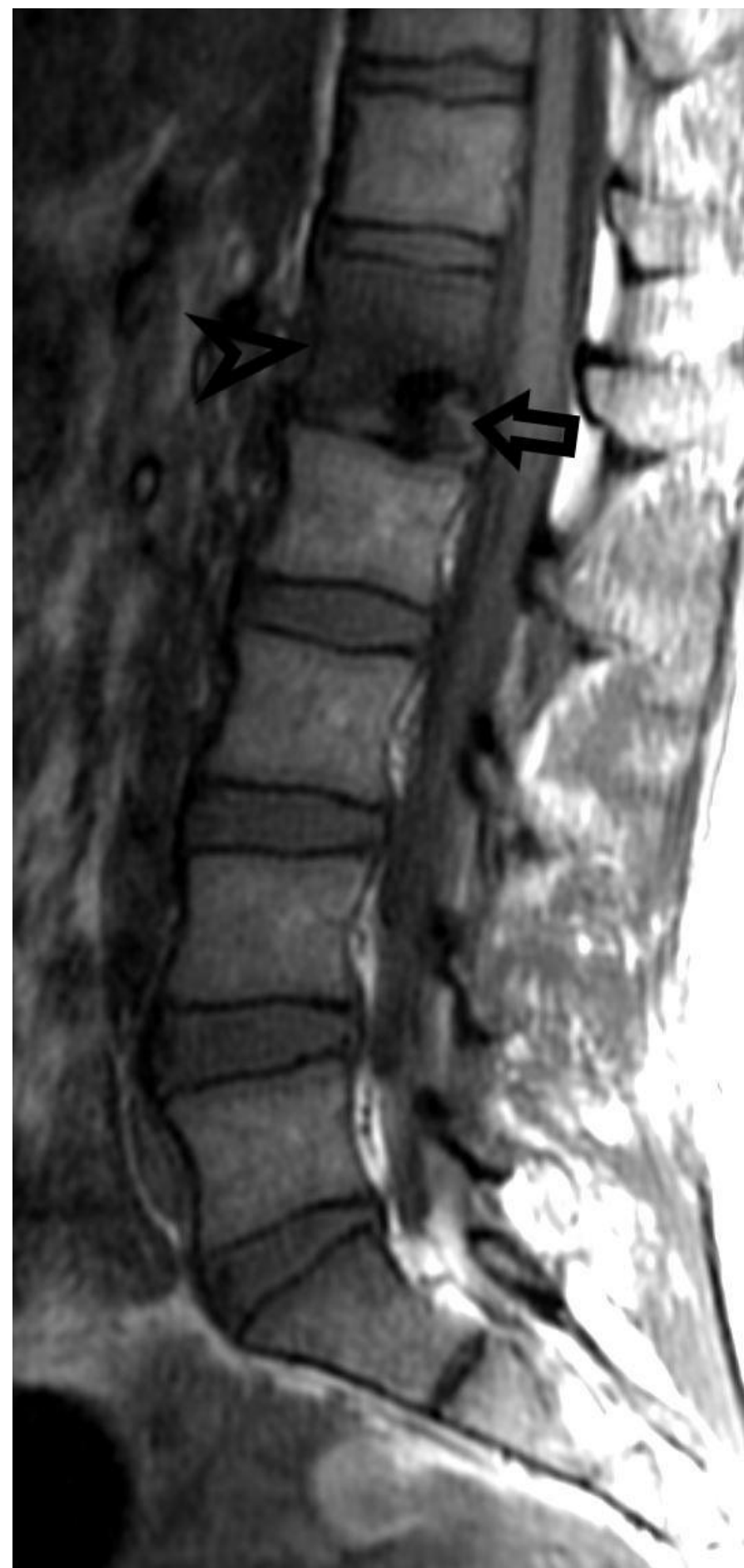

Figure 6: 24-year-old female patient: Diagnosis of Calcific Discitis.

Findings: Sagittal T1 image of the spine demonstrates a T2hypointense lesion within the intervertebral disc space at L1L2 (arrow) with low T1 signal intensity throughout the L1 vertebral body (arrowhead).

Technique: Model: Siemens Somatom; TE: 8.952; TR: 350.

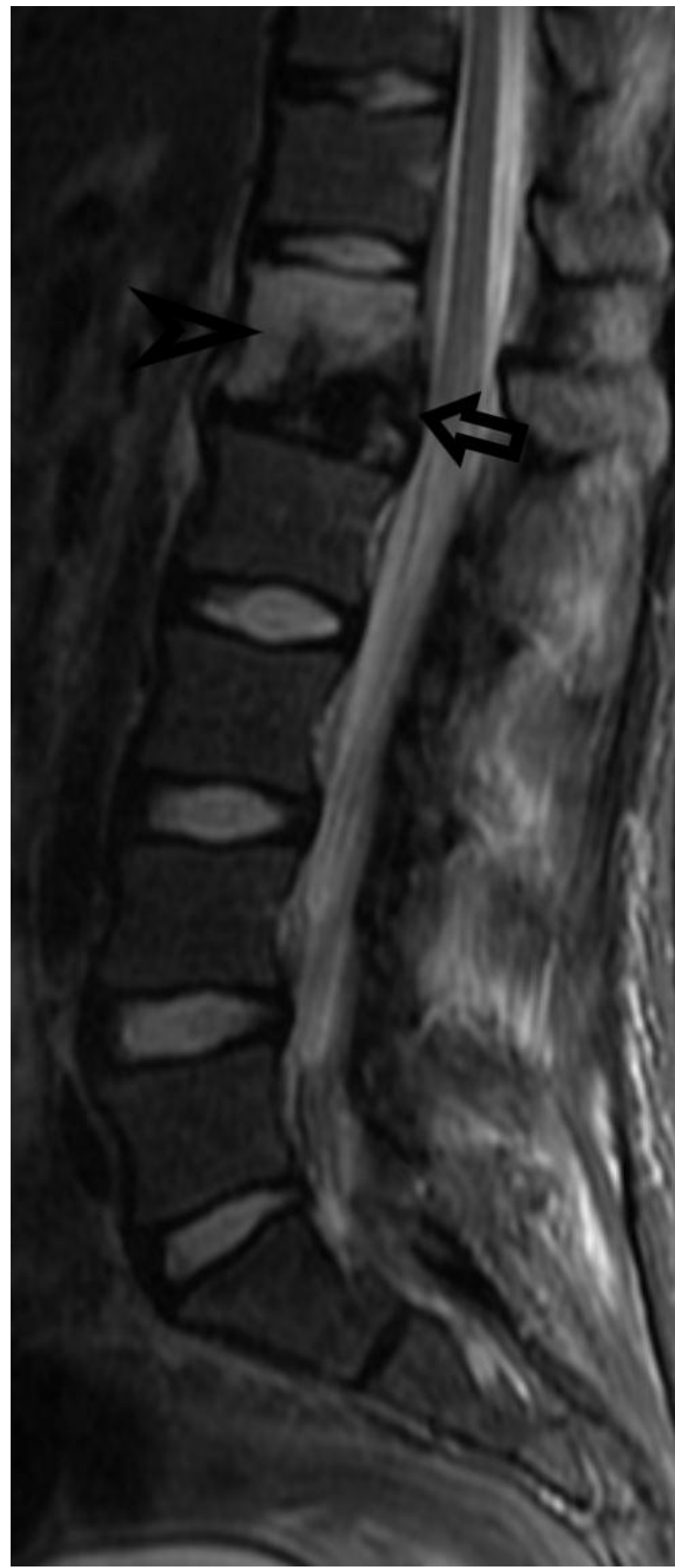

Figure 7: 24-year-old female patient: Diagnosis of Calcific Discitis.

Findings: Sagittal STIR image of the spine demonstrates a T2hypointense lesion within the intervertebral disc space at L1L2 (arrow) with marrow edema throughout the L1 vertebral body (arrowhead). There is mild associated spinal canal stenosis.

Technique: Model: Siemens Somatom; TE: 43.84; TR: 3991. 


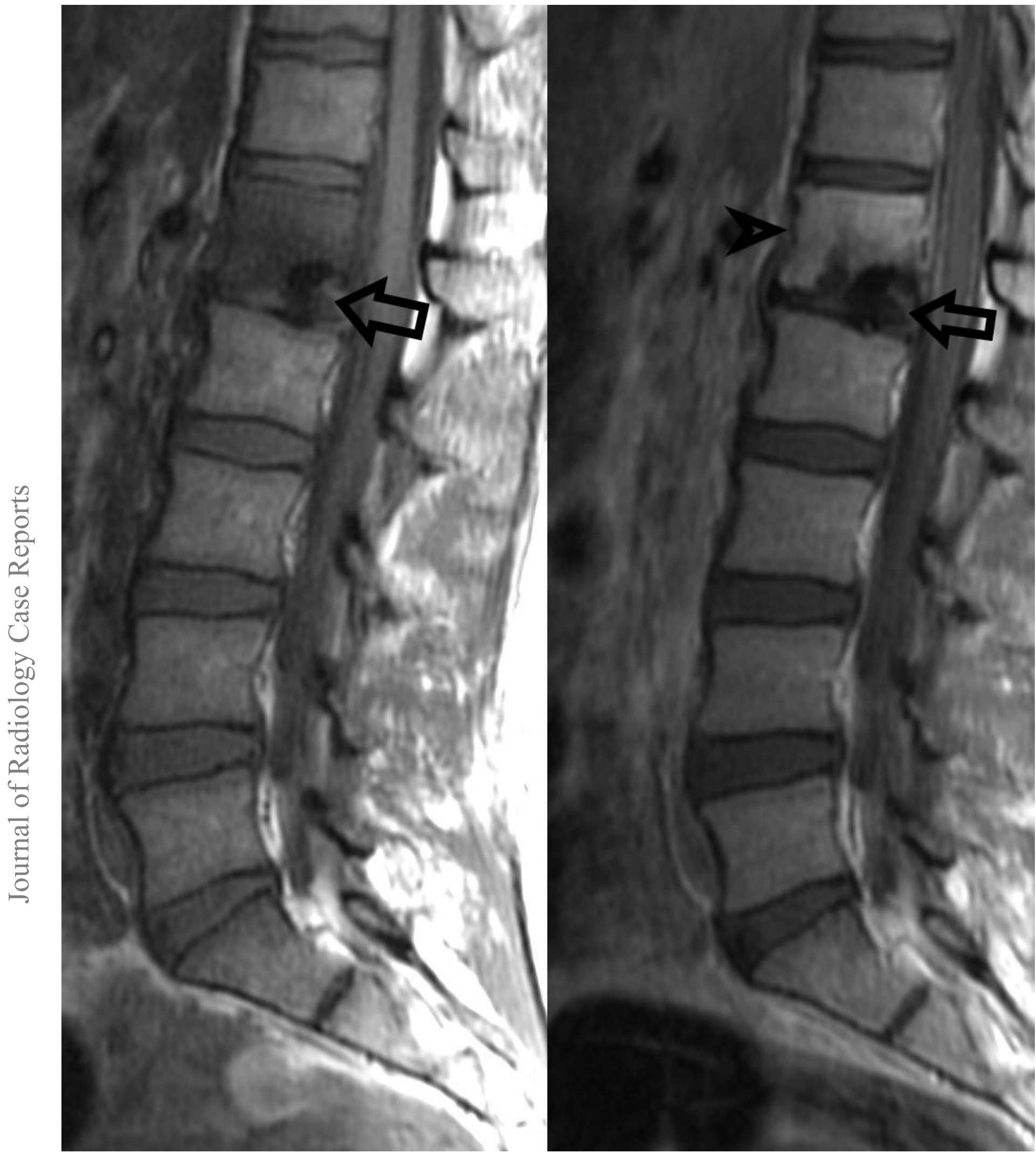

Figure 8: 24-year-old female patient: Diagnosis of Calcific Discitis.

Findings: Sagittal pre- and post-contrast images of the spine demonstrates a T1-hypointense lesion within the intervertebral disc space at L1-L2 (arrows) with enhancement throughout the L1 vertebral body (arrowhead).

Technique (post-contrast): Model: Siemens Somatom; TE: 8.84; TR: 532. 


\begin{tabular}{|l|l|}
\hline Etiology & Proposed mechanisms include microtrauma, infection, and inflammation \\
\hline Incidence & 39 cases \\
\hline Gender Ratio & 2F:1M \\
\hline Age Predilection & Mean age: 46 \\
\hline Risk Factors & $\begin{array}{l}\text { Idiopathic though it is proposed that vertebral body and/or endplate weakness contributes to intravertebral } \\
\text { herniation }\end{array}$ \\
\hline Treatment & Non-steroidal anti-inflammatory drugs and activity restriction \\
\hline Prognosis & Excellent: full recovery unless associated herniation occurs \\
\hline Image Findings & MRI: T1/T2 hypointensity of intravertebral disc space. CT: calcification of IV disc \\
\hline
\end{tabular}

Table 1: Summary table for Calcific Discitis.

\begin{tabular}{|c|c|c|c|c|c|}
\hline $\begin{array}{c}\text { Differential } \\
\text { Diagnosis }\end{array}$ & X-Ray & US & CT & MRI & PET \\
\hline $\begin{array}{l}\text { Infective } \\
\text { spondylodiscitis }\end{array}$ & $\begin{array}{l}\text { Nonspecific early } \\
\text { in disease course. } \\
\text { IV disk space } \\
\text { narrowing, end- } \\
\text { plate } \\
\text { involvement, and } \\
\text { possibly sclerosis }\end{array}$ & N/A & $\begin{array}{l}\text { Confirms X-ray } \\
\text { findings. Better } \\
\text { characterizes disc } \\
\text { calcification. }\end{array}$ & $\begin{array}{l}\text { T1-weighted MRI will show } \\
\text { hypointensity or isointensity } \\
\text { while T2-weighted MRI will } \\
\text { show hyperintensity of the } \\
\text { endplates and within the IV } \\
\text { disk. Gadolinium contrast } \\
\text { MRI will show enhancement } \\
\text { of the subchondral bone or } \\
\text { vertebral body }\end{array}$ & $\begin{array}{l}{ }^{18} \mathrm{~F}-\mathrm{FDG} \text { yields } \\
\text { increased } \\
\text { uptake in spinal } \\
\text { infection versus } \\
\text { normal bone } \\
\text { marrow in } \\
\text { degenerative } \\
\text { processes }\end{array}$ \\
\hline Osteoid osteoma & $\begin{array}{l}\text { Periosteal } \\
\text { reaction with } \\
\text { cortical } \\
\text { thickening. }\end{array}$ & $\begin{array}{l}\text { Show } \\
\text { hypoechogenic } \\
\text { center with } \\
\text { surrounding } \\
\text { posterior } \\
\text { acoustic } \\
\text { enhancement }\end{array}$ & $\begin{array}{l}\text { Circumscribed lucent } \\
\text { region. enhances the } \\
\text { characteristics found } \\
\text { on x-ray, with a } \\
\text { lucent center and } \\
\text { surrounding sclerosis }\end{array}$ & $\begin{array}{l}\text { Insensitive. Hyperemia and } \\
\text { surrounding bone marrow } \\
\text { edema }\end{array}$ & $\begin{array}{l}\text { "double- } \\
\text { density" sign }\end{array}$ \\
\hline Osteoblastoma & $\begin{array}{l}\text { Internal } \\
\text { calcifications }\end{array}$ & N/A & $\begin{array}{l}\text { reactive sclerosis. } \\
\text { show internal } \\
\text { calcifications }\end{array}$ & $\begin{array}{l}\text { T1-weighted MRI can show } \\
\text { hypointense to isointensity } \\
\text { and T2-weighted MRI } \\
\text { typically demonstrates } \\
\text { isointense to hypointense } \\
\text { lesions. contrast-enhanced } \\
\text { MRI is avid }\end{array}$ & $\begin{array}{l}\text { Non-specific } \\
\text { intense uptake }\end{array}$ \\
\hline $\begin{array}{l}\text { Intervertebral } \\
\text { disc herniation }\end{array}$ & Poorly visualized & N/A & $\begin{array}{l}\text { CT myelography is } \\
\text { gold standard }\end{array}$ & $\begin{array}{l}\text { Study of choice for } \\
\text { visualizing disc } \\
\text { herniations/bulges }\end{array}$ & N/A \\
\hline $\begin{array}{l}\text { Vertebral } \\
\text { spondylosis }\end{array}$ & $\begin{array}{l}\text { Horizontal bony } \\
\text { projections from } \\
\text { vertebral body } \\
\text { margins, most } \\
\text { commonly } \\
\text { anterior and } \\
\text { lateral projections }\end{array}$ & N/A & $\begin{array}{l}\text { Horizontal } \\
\text { projections from } \\
\text { vertebral body } \\
\text { margins, most } \\
\text { commonly anterior } \\
\text { and lateral } \\
\text { projections }\end{array}$ & $\begin{array}{l}\text { Applicable when } \\
\text { complications are present }\end{array}$ & N/A \\
\hline
\end{tabular}

Table 2: Differential diagnosis table for Calcific Discitis. 


\section{ABBREVIATIONS}

CD: Calcific discitis

$\mathrm{cm}$ : Centimeters

CT: Computed Tomography

kvp: Peak kilovoltage

mA: Milliampere

MHz: Megahertz

mL: Milliliters

MRI: Magnetic Resonance Imaging

N/A: Not Applicable

T1WI: T1-Weighted Imaging

T2WI: T2-Weighted Imaging

US: Ultrasound

KEYWORDS

Calcific; Discitis; CT; Back Pain; Calcium; Spine

\section{Online access}

This publication is online available at:

www.radiologycases.com/index.php/radiologycases/article/view/3728

\section{Peer discussion}

Discuss this manuscript in our protected discussion forum at: www.radiolopolis.com/forums/JRCR

\section{Interactivity}

This publication is available as an interactive article with scroll, window/level, magnify and more features.

Available online at www.RadiologyCases.com

\section{Published by EduRad}

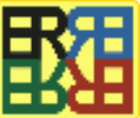

www.EduRad.org 